\title{
Evolution of seismicity at Kiruna Mine
}

\author{
S Dineva Luleå University of Technology, Sweden \\ M Boskovic Luossavaara-Kiirunavaara Aktiebolag (LKAB), Sweden
}

\begin{abstract}
Kiirunavaara (Kiruna) iron ore mine owned by $L K A B$ (Sweden) is one of the largest underground mines. Mining started in 1898 as an open pit mine. In mid-1950, the mine started a transition to underground mining and passed to only underground mining in 1962. More substantial problems with seismicity started in 2007-2008 when the deepest mining level was $907 \mathrm{~m}$ (ca. $670 \mathrm{~m}$ below surface). By 2016, the mining production is at 1,022-1,079 m Level (ca. 785-845 m below surface). More than one billion tonnes of ore have been extracted since the beginning of mining. The average yearly production in recent years is 28 million tonnes.
\end{abstract}

By 2016 the mine has the largest underground seismic system in the world with 204 operational geophones. The number of the sensors (geophones with natural frequencies of 4.5, 14, and a few of $30 \mathrm{~Hz}$ ) changed with the increasing of production depth. The major stages with seismic system upgrades are: August 2008-June 2009 with 112 installed geophones, and July 2012-September 2013 with 95 installed geophones. During 2016-2017 it is planned to install some additional 45 geophones.

The study was carried out to identify some trends in seismicity as the mining goes deeper and to find the correlation with some main controlling parameters - volume and depth of the production in order to obtain information for future seismic hazard and risk analysis. Custom made applications within mXrap were utilised to carry out the spatial variations of seismicity.

The analysis showed substantial difference between the seismicity in the three studied blocks -15/16, 28/30, and 33-37/34, with the weakest seismic activity in Block 15/16 ( $M_{\max } 1.6$, maximum observed magnitude), followed by Block 28/30 ( $\left.M_{\max } 2.2\right)$, and then largest seismicity in Block 33-37/34 ( $\left.M_{\max } 2.2\right)$. The daily seismicity rate increased substantially through the years only for Block 33-37/34. The seismicity correlates strongly with the production depth. In general a straightforward correlation between the production volume and number of larger events $(M>0)$ was not found for the three studied blocks, assuming there are other factors affecting the seismicity, e.g. geological structures, areas with contrast in geomechanical properties, etc. The spatial variations of some seismic source parameters were traced for varying periods of time, depending on the major production stages (opening of new levels, full production, closing) for the three blocks. The distributions of the cumulative seismic energy showed a maximum around and below the production. The cumulative seismic moment and number of events in most cases showed a maximum around and above the production, indicating caving in these areas. The static stress drop shows the largest values around and below the production on the footwall side, corresponding also to the areas with increased stress. The energy index showed increased stresses in the same areas $(E I>1)$.

This study is only the first overview of the seismicity in Kiruna Mine. For seismic hazard assessment and risk analysis further more detailed studies with smaller time intervals need to be carried out to obtain more precise correlations between the seismic parameters and the production volume and depth, and other possible factors affecting seismicity (geological structures, areas with contrast geomechanical properties, etc.).

Keywords: mining-induced seismicity, underground deep mining, rockbursts

\section{Introduction}

Kiirunavaara (Kiruna) iron ore mine owned by LKAB (Sweden) is one of the world's largest underground mines. Mining started in 1898 as an open pit mine. In mid-1950, the mine started a transition to underground mining 
and passed to only underground mining in 1962. More substantial problems with seismicity started in 2007-2008 when largest mining depth was at Level 907 (670 m below the surface). By 2016, the mining production is at Levels 1,022-1,079 (785-855 $\mathrm{m}$ below the surface). More than one billion tonnes of ore have been extracted since the beginning of mining. The average yearly production in recent years is 28 million tonnes.

By 2016 the mine has the largest underground seismic system with 204 operational geophones. The number of the sensors (geophones with natural frequencies of $4.5,14$, and a few of $30 \mathrm{~Hz}$ ) changed with the increasing of production depth. The major stages with seismic system upgrades are: August 2008-June 2009 with 112 installed geophones and July 2012-September 2013 with 95 installed geophones. During 2016-2017 it is planned to install an additional 45 geophones.

The mining method in Kiruna Mine today is sublevel caving where crosscuts are driven from the footwall through the orebody with a distance of $25 \mathrm{~m}$ between them. The spacing between production levels is $29 \mathrm{~m}$. Fan shaped patterns with 10 to 13 holes and $3 \mathrm{~m}$ burden are drilled with remote controlled rigs in all crosscuts. The fans are charged with approximately $2,500 \mathrm{~kg}$ of emulsion and each fan contains around $10,000 \mathrm{t}$ of ore. Electric load-haul-dump machines remove the ore to orepasses that connect to the main haulage level at $1,365 \mathrm{~m}$. The ore is loaded by gravity from the orepasses into remotely controlled shuttle trains that transport the ore to a series of primary crushers. The ore is then hoisted in two stages to the sorting plant at the surface.

In Kiruna Mine the orebody is divided into 10 production blocks, named according to the north-south direction (Y coordinate). During the transition from old haulage level at 1,045 to the new one at 1,365 Level, the names and borders between production blocks have been changed and the new production blocks named according to the new $Y$ coordinates down to the 1,400 $\mathrm{m}$ Level $(\mathrm{Z})$. In the east-west direction $(\mathrm{X})$ the borders of the studied blocks are defined by the distance of the infrastructure in the footwall $(100 \mathrm{~m}$ from the footwall structure) and hanging wall contact (defined by the orebody in $m$ Xrap). Here the seismicity was studied in three blocks, which are defined by the new coordinates from the surface down to $1,400 \mathrm{~m}$ Level. The coordinate ranges of the studied blocks are shown in Table 1.

Table 1 Coordinate ranges for the studied Block 15/16, Block 28/30 and Block 33-37/34

\begin{tabular}{lllllll}
\hline \multirow{2}{*}{ Block } & \multicolumn{2}{c}{ East-west (X) } & \multicolumn{2}{c}{ North-south (Y) } & \multicolumn{2}{c}{ Up-down (Z) } \\
\cline { 2 - 7 } & Start & End & Start & End & Start & End \\
\hline B15/16 & 6,000 & 6,500 & 1,400 & 1,800 & -236 & $-1,400$ \\
B28/30 & 6,000 & 6,600 & 2,720 & 3,100 & -200 & $-1,400$ \\
B33-37/34 & 6,100 & 6,700 & 3,100 & 3,700 & -200 & $-1,400$ \\
\hline
\end{tabular}

The aim of this study was to follow the developments in seismicity with the mining going deeper starting from the end of 2008, when significant induced seismicity started, until July 2016:

- We wanted to see if the number of events and maximum observed magnitudes increased during the study period.

- We followed the mining seismicity in depth to find if it correlates with the production depth and production volume.

- We explored the spatial variations in seismic source parameters (cumulative released seismic energy and seismic moment (co-seismic deformation)) during the production phases and possible correlation between the two parameters.

- We looked at spatial variations of some stress indicators (average stress drop and energy index) during the production phases. 
The analysis was done block-by-block and level-by-level (for the production phases) and the results were compared. The final aim was to gain insights into the seismic process as a function of some main controlling factors, production volume and depth that could be used later for seismic hazard and risk assessments, as well as to find possible indicators of increased seismicity or larger seismic events caused by the larger depth of mining. The most important tool used in this study was the mXrap software (Harris \& Wesseloo 2015), employing the Grid Based Analysis app (Wesseloo \& Harris 2015) explained in more detail in Wesseloo et al. (2014). This mXrap app was custom modified by Johan Wesseloo and Paul Harris (Australian Centre for Geomechanics) with new applications for the purpose of this study.

As Kiruna Mine is almost 4,500 m long and the seismicity rate is high we concentrated only on a few areas (blocks) with different characteristics of seismicity and frequency of rockbursts - Block 15/16 (with comparatively low seismicity), 28/30 and 33-37/34 (with highest seismicity and number of rockbursts). The seismicity for a one-year period (June 2015-July 2016), the position of the studied blocks, and the seismic sensor locations by 2016 are shown in Figure 1.
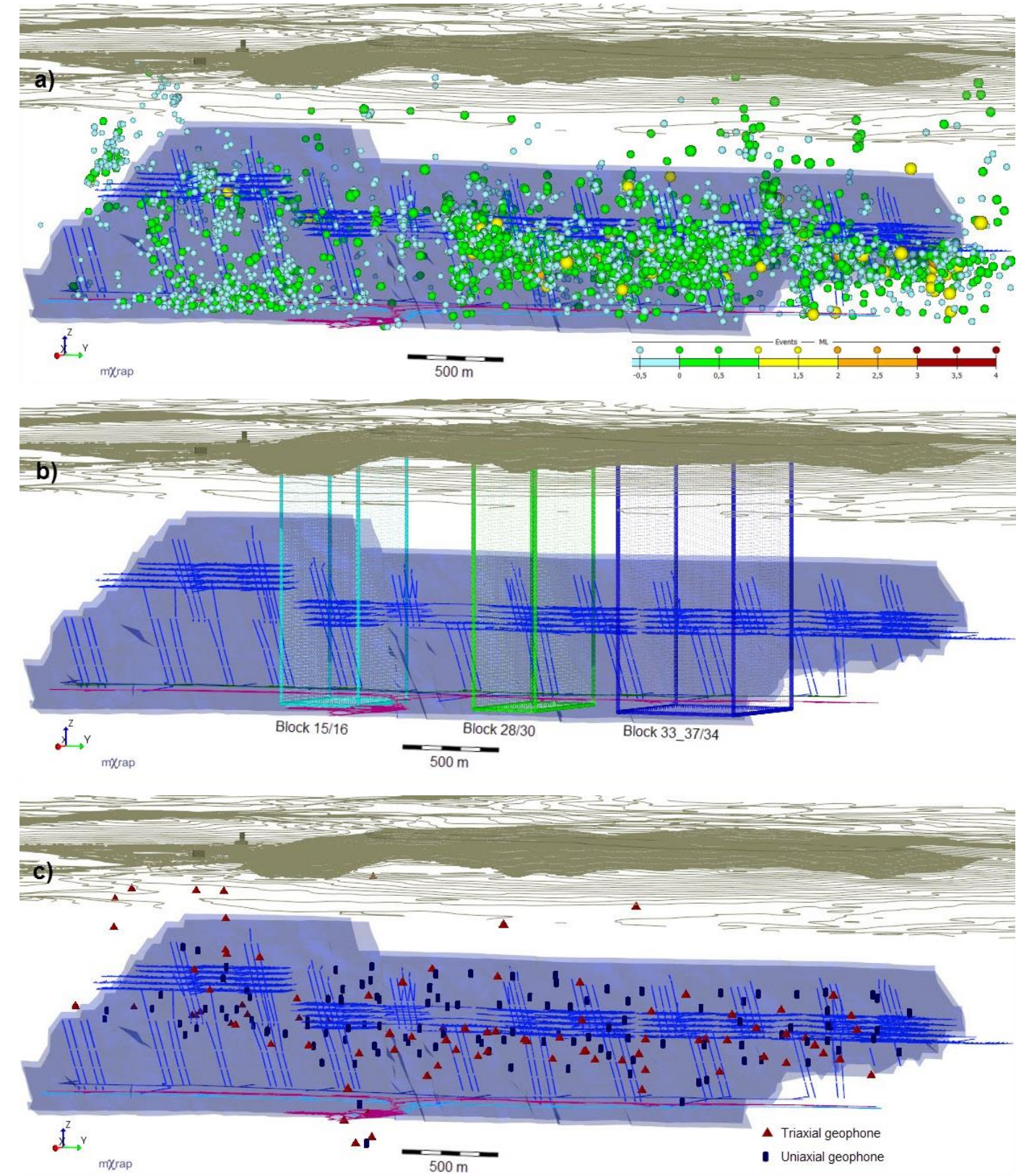

Figure 1 (a) Seismicity in Kiruna Mine for period June 2015-July 2016; (b) outline of studied blocks; (c) seismic sensor locations by 2016 . The size of the spheres representing the seismic events (a) is proportional to the local magnitude $\mathrm{M}$. The orebody is shown as a shaded area. The production 
levels between 2008 and 2016, as well as the orepasses and the haulage level are also shown. The isolines on the top of each plot are the surface topography

In order to discriminate orepass noise (recorded non-seismic events, as dumped rock bouncing in the orepass), an ellipsoidal volume with a horizontal section of $50 \times 3 \mathrm{~m}$ along the orepasses was excluded from the analyses. The hanging wall events were excluded too.

\section{Seismic system sensitivity}

The first geophones in Kiruna Mine were installed in 2003 in the northern part of the mine called Lake Ore in attempt to follow the caving of the crown pillar. The first major stage in the seismic system upgrades started in August 2008 and was completed in June 2009 with 112 installed geophones. The second upgrade lasted from July 2012 until September 2013 with 95 installed geophones. Four periods with different sensor coverage were defined (Figure 2), following the seismic sensor installation campaigns. To define the minimum well recorded magnitude (threshold magnitude, e.g. Kijko \& Funk (1994)) we used Gutenberg-Richter graphs (G-R) (Gutenberg \& Richter 1956). Figure 2 shows the graphs for each period and the corresponding block.

Block 15/16

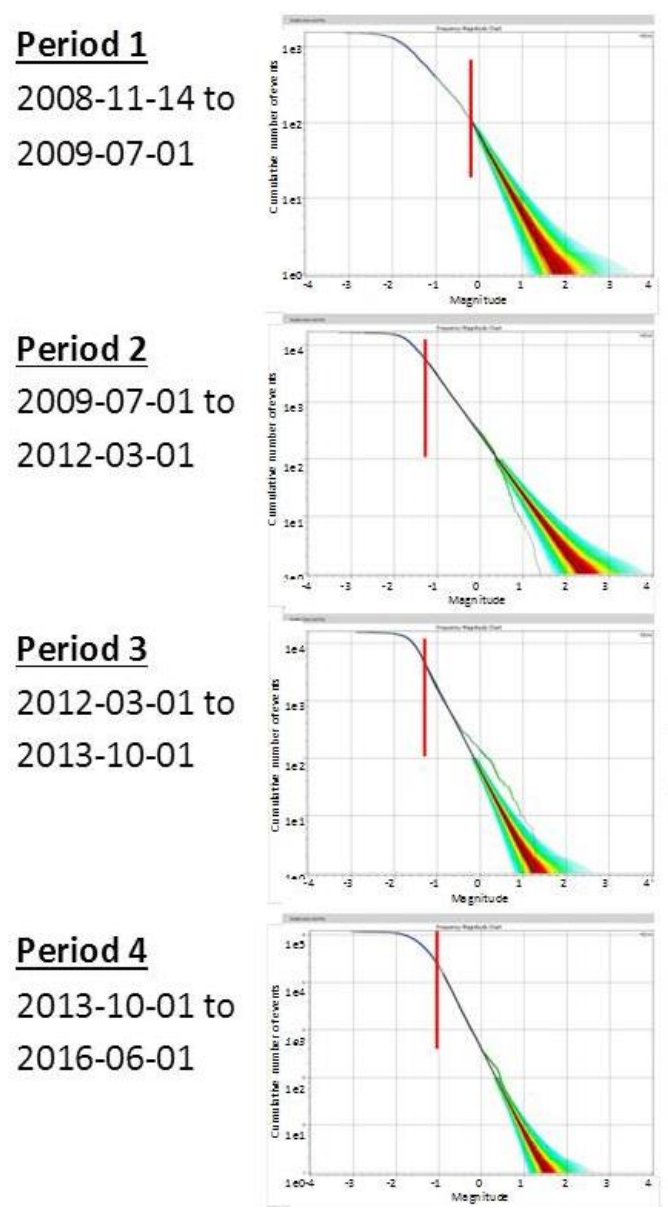

Block 28/30
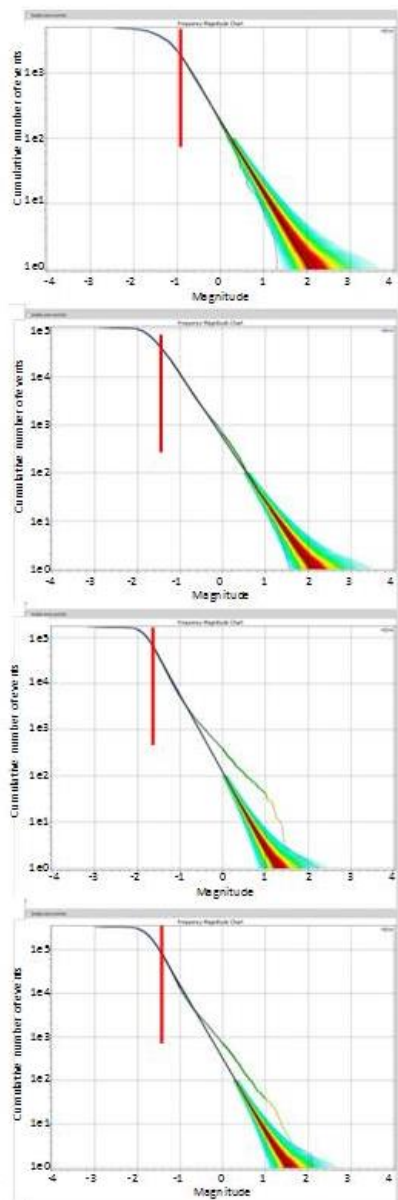

Block 33-37/34
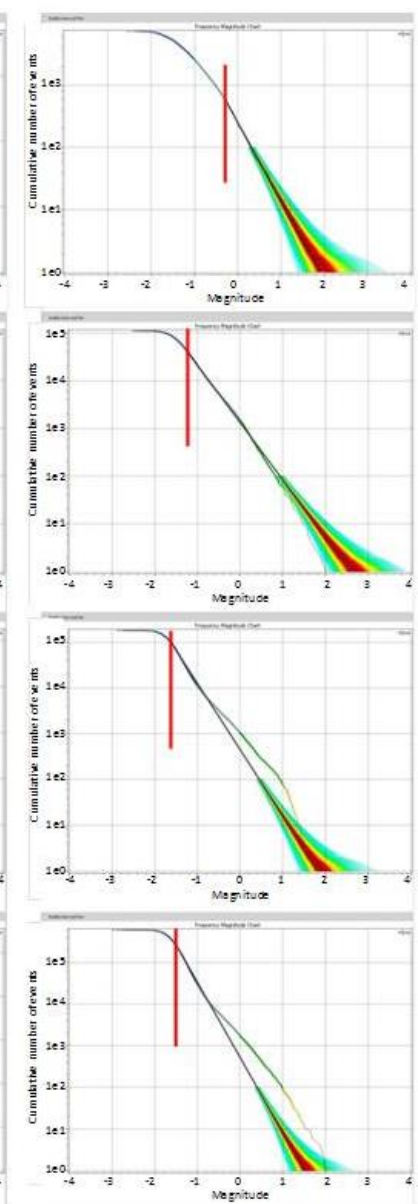

Figure 2 Cumulative G-R graphs for all studied blocks and time periods with different sensitivity of the seismic system (mXrap software). The red vertical lines define the threshold magnitude

The magnitude used in this study is local magnitude defined by the Institute of Mine Seismology (IMS) as $M=0.272 \log E+0.392 \log P-0.523$ ( $E=$ energy of the event and $P=$ potency). For sensitivity analysis the events between $-700 \mathrm{~m}$ and $-1,400 \mathrm{~m}$ (mine $Z$ coordinate) were included in the study. In this way the events in the hanging wall, which are located with much lower accuracy than the events in the footwall were 
excluded. It has to be mentioned that the real depth under the earth surface and the mining levels differ by $236 \mathrm{~m}$ as the zero level was chosen at the beginning of the mining on the top of a small hill. All the levels mentioned further on are the mining levels.

The G-R graphs provide a lot of information about the seismicity and seismic hazard. Our aim here was to use them only for defining the threshold magnitude or magnitude of completeness $\left(M_{\min }\right)$. Although not all graphs follow strictly a linear trend we can still define the threshold magnitudes for each block and period of time, shown by red vertical lines on Figure 2. In general the threshold magnitude decreased with time as the number of the sensors increased and the spatial coverage improved. In Blocks 28/30 and 33-37/34 $\mathrm{M}_{\text {min }}$ decreased from -0.3 to -0.4 in Period 1 down to -1.3 to -1.4 in Period 4. There was slightly lower $M_{\min }$ in Period 3 than in Period 4 (by 0.2 magnitude units), a difference within the average error of magnitude estimation. $M_{\min }$ for Block 15/16 decreased in overall from -0.2 in Period 1 down to -1.4 in Period 4 . It has to be noted that during Period 2 and $3 \mathrm{M}_{\min }$ was lower, down to -1.2. The difference in $\mathrm{M}_{\min }$ for Periods 2, 3 and 4 is also in the order of the magnitude estimation error. There is no obvious reason for lower $\mathrm{M}_{\min }$ in Periods 2 or 3 compared to Period 4 as the number of sensors and sensors coverage only increased from Period 1 to 4 .

More information from G-R graphs (e.g. maximum expected magnitude for each block and period of time and slope of the graphs) can be obtained only after additional analysis of the cases where the empirical data deviate from the linear trend (nine out of 12 cases) using more detailed analysis, e.g. Kijko and Sellevoll (1989), Kijko and Graham (1998), Kijko (2004), taking into account the conclusions from Lasocki and Urban (2011).

\section{Changes in seismicity with time (production depth)}

Seismicity in mines is a complex function of many parameters related to mining (production depth, production stage and rate, total production volume or tonnage, etc.) and geomechanical and geological factors (contrast in the geomechanical properties, geological structures, etc.). Here we tried to follow the changes in seismicity in terms of number of events (seismicity rate) above the threshold magnitude for the whole period from November 2008 until July 2016 and maximum observed magnitude. The changes in seismicity rate are normalised by the production volume separately for each block and period of time.

\subsection{Number of events}

The number of events is estimated as the total number above magnitudes 0 and 1 . These events present a more serious problem for mine safety. The total number of events above a certain magnitude is normalised by the duration of the period of time, for which it is calculated and then normalised by the production volume for the same block and period of time. The results are presented in Figure 3. The normalisations for Figures 3(a) and (c) are calculated as $\overline{N_{i}}=\frac{N_{i}}{D_{i}}$, and for Figures $3(\mathrm{~b})$ and (d) as $\overline{\overline{N_{i}}}=\frac{N_{i}}{D_{i} V_{i}}$, where $\mathrm{N}_{\mathrm{i}}$ is the total number of events above a certain magnitude for period $i=1, . ., 4$, defined in Figure 2 . $D_{i}$ and $V_{i}$ are respectively the number of years and the total number of produced tonnes in the corresponding block for period $i$. In this way a trend in time can be noticed for each block. The total production in each block and period of time is also shown for comparison with the number of events (Figure 3(e)).

The number of events on the graphs normalised only by the duration of the period (Figures $3(\mathrm{a})$ and (c)) varies from block to block and as expected it is lowest for Block 15/16, followed by Block 28/30 and then Block 33-37/34, independently of the magnitude interval. The production in Block 15/16 is the weakest from all blocks (Figure 3(e)), followed by the production in Block 28/30, and then Block 33-37/34. For $M>0$ the number of events per day (daily rate) increased only for Block 33-37/34 and stayed almost the same in the other two blocks. For $M>1$ the trend is different, with a decrease in the daily rate for Block 15/16, and general increase for the other two blocks with a maximum in Period 3.

The daily rates of seismicity normalised by the production (Figures $3(b)$ and (d)), could be expected to show no change if the seismicity was related to the production. This is not the case. There is a significant change from Period 1 to Period 2. The production in Period 1 was a few times less than in the other periods. Because of this 
after a normalisation of the daily seismicity rate by the production we obtained a maximum in the graphs for $M>0$ and $M>1$. As controlled blasting was introduced in Period 2 , the change in the daily rate possibly could be explained by it, e.g. the change of the blasting pattern affected the relationship between the seismicity and the production. After Period 2 the normalised daily seismicity rate did not change significantly for events with $M>0$, except a small increase in Period 3 in Block 33-37/34. For the events with $M>1$ the rate was almost the same (very low) in Block 15/16 after Period 2. Maximum is observed in Period 3 for Block 28/30 and Block 33-37/34 due to the increased seismicity rate during this period and decreased production.

In general a straightforward correlation between the production and number of larger events $(M>0)$ was not found for the three studied blocks. A significant increase in the number of events with $M>0$ was found only for Block 33-37/34. Further analysis needs to be made of the trends of seismicity for smaller time intervals.

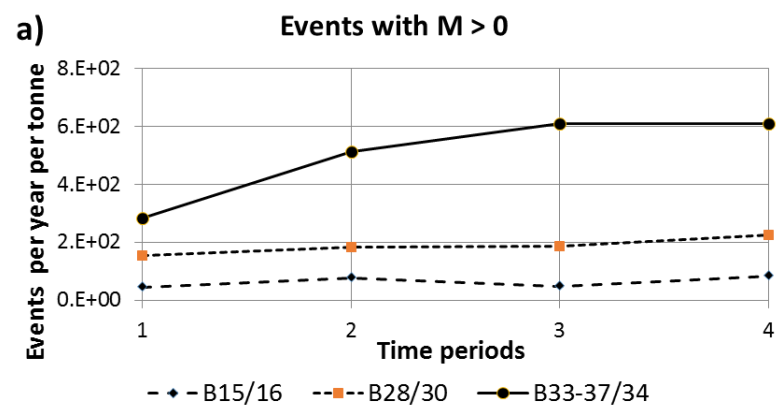

b) Events with $\mathrm{M}>\mathbf{0}$ (normalised)

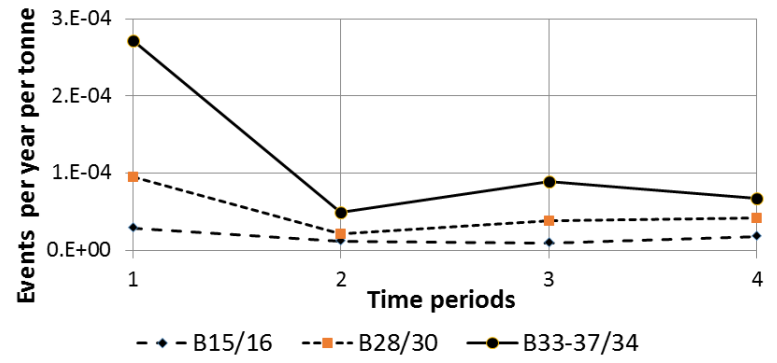

d) Events with $M>1$ (normalised)

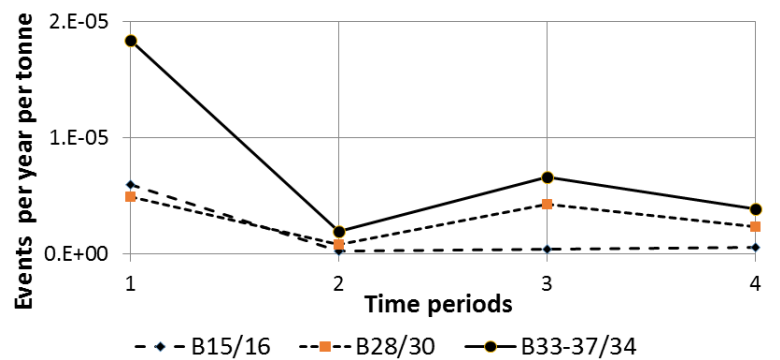

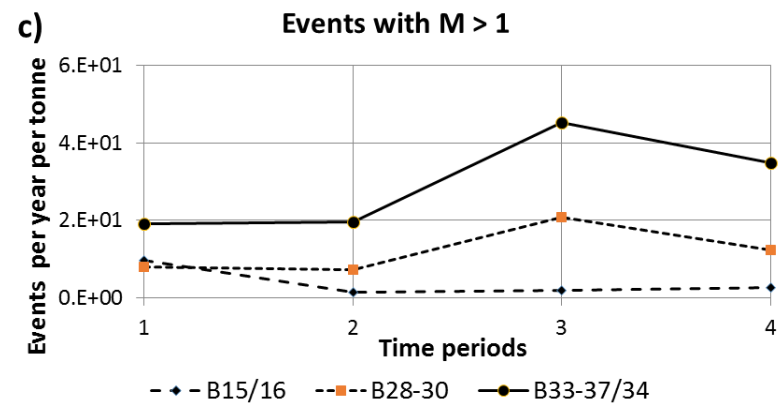

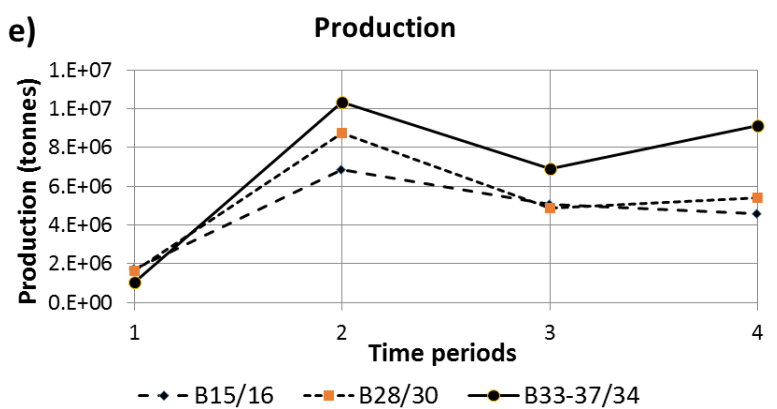

Figure 3 Number of seismic events per year with magnitude $M>0$ (a) and $M>1$ (c). Normalised number of events per year by the production in tonnes for the same block and period of time with $M>0$ (b) and with $M>1$ (d). Total production for each period of time per block (e). Time periods correspond to the periods in Figure 2

\subsection{Maximum observed magnitude}

The maximum observed magnitude is one of the main criteria for increased seismic hazard and it is important to find if it changes with time (corresponding to changes in the production depth). The observed maximum magnitude for the studied blocks and periods of time with different seismic system sensitivity are shown on Figure 4. We can see that the maximum observed magnitude dropped slightly for Block 15/16 from 1.6 to 1.3 , and then increased to 1.4. There was almost no change for Block 33-37/34 (1.8 to 2.0) but for Block 28/30 
there was significant increase between Period 1 and 3 ( 0.9 magnitude units, from 1.3 to 2.2 ) followed by a slight decrease in Period 4.

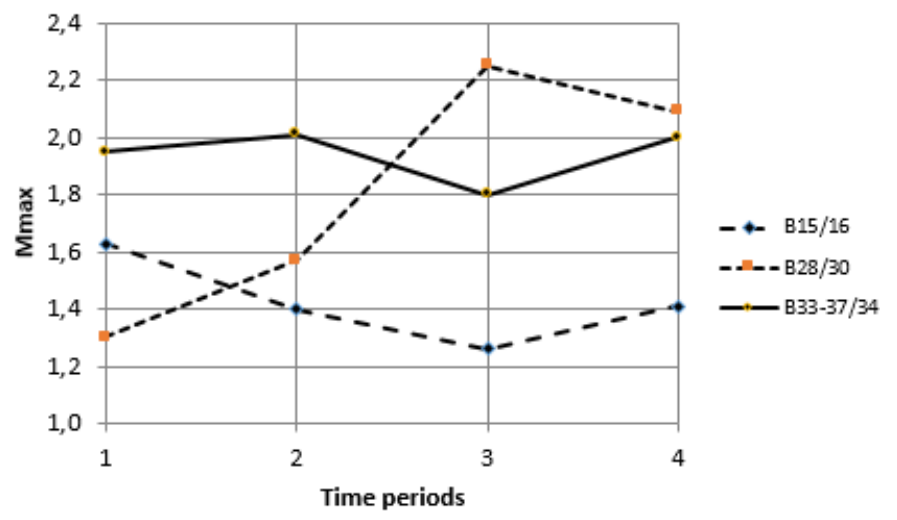

Figure 4 Maximum observed magnitude for three studied blocks for time periods corresponding to the periods in Figure 2

\subsection{Number of events and seismic energy compared to production depth}

Depth of the seismic events is an important factor that can be related to the maximum stresses and possibly correlates with the mining production depth. We assumed that there is another factor - the phase of the production at each level, which also plays a role in seismicity pattern. To evaluate the changes in the seismicity depth in correlation with the production level and phase, the production at each level was analysed and three separate phases were defined - A (opening of the production in the block), B (full production), and $\mathrm{C}$ (closing of the production in the block). Each one of these phases should correspond to a different state of the rock mass, starting from solid rock with high strength and gradually decreased strength and increased stresses due to the openings. The opening phase $(A)$ was defined from the start of the production in the block until the blasted fans in at least half of the crosscuts in that block reached the upper level. The closing phase (C) was defined by the percentage $(10 \%)$ of remaining fans to blast, in at least half of the crosscuts but no more than 10 fans per crosscut. Phase $B$ is defined as the phase between $A$ and $C$. The duration of the phase, total number of events with $M>-0.4$, and maximum observed magnitude during the phase are shown also in the Table 2. It has to be noted that there is some overlap between the closing phase (C) for the level and the opening phase (A) for the level below it (Table 2).

Seismic data was analysed for each one of the identified phases and compared with the production depth and volume. The number of the events as a function of depth was counted for bins of $50 \mathrm{~m}$ depth. The cumulative energy was calculated for each depth interval for the same bins. The number of events and cumulative energy were normalised by the duration of the corresponding phase (in days). The results for all three phases for each level/block were compared. The production for the same phases was calculated too. Examples of the results for Levels 964 and 993 for Block 28/39 and for Block 33-37/34 are presented in Figures 5 and 6 , respectively.

The results from the analysis of the depth distribution of the number of events and cumulative seismic energy showed that there is a strong correlation between the depth where the maximum number is observed, cumulative energy, and the production depth. In most cases the peaks in the number of events and energy correspond to the production depth but in some cases (B28-993, B30-1051, B33+37-993) the peaks in the number of events and the energy are below the production level. In two cases (B28-964 and B33+37-964) a significant number of events occurred also above the production level. There is comparatively good correspondence between the depth for the peak in the number of events and cumulative energy. The depth distributions for B16-935 are different from the rest as a large maximum is observed much lower than the production level in both the number of events and energy. 
The comparison of the graphs for different phases shows that in many cases the seismic activity (number of events) is largest for the opening phase (A) (cases B28-964, B30-1022, B30-1051, B34-1022). In one case (B33+37-993) the peaks of seismic activity and the cumulative energy for the full production phase are the largest. 
Table 2 Phases in production for Blocks B15/16, B28/30, and B33-37/34 studied here. Phase $A$ corresponds to the opening of the level, phase $B$ full production, phase $C$ closing of the level

\begin{tabular}{|c|c|c|c|c|c|c|c|c|}
\hline Block & Level & Phase & Phase start & Phase end & $\begin{array}{l}\text { No. } \\
\text { days }\end{array}$ & $\begin{array}{l}\text { No. } \\
\text { events }\end{array}$ & Max. mag. & Production (Mt) \\
\hline B16 & 935 & $A$ & $6 / 7 / 2008$ & $15 / 4 / 2009$ & 284 & 43 & 1.6 & 1.7 \\
\hline B16 & 935 & B & $16 / 4 / 2009$ & $13 / 2 / 2015$ & 2,131 & 429 & 1.4 & 15.0 \\
\hline B16 & 935 & $\mathrm{C}$ & $14 / 2 / 2015$ & $7 / 7 / 2015$ & 143 & 170 & 1.3 & 1.2 \\
\hline B16 & 964 & $A$ & 23/12/2009 & $30 / 6 / 2016$ & 2,382 & 482 & 1.4 & 16.0 \\
\hline B16 & 993 & $A$ & $23 / 10 / 2015$ & $30 / 6 / 2016$ & 252 & 123 & 1.4 & 0.6 \\
\hline B28 & 964 & $A$ & $17 / 2 / 2010$ & $10 / 12 / 2010$ & 297 & 575 & 1.4 & 2.9 \\
\hline B28 & 964 & B & $11 / 12 / 2010$ & $14 / 9 / 2011$ & 278 & 319 & 1.1 & 2.3 \\
\hline B28 & 964 & C & $15 / 9 / 2011$ & $4 / 4 / 2012$ & 203 & 282 & 1.2 & 1.9 \\
\hline B28 & 993 & $A$ & $12 / 7 / 2011$ & $20 / 7 / 2012$ & 375 & 440 & 1.7 & 3.0 \\
\hline B28 & 993 & B & $21 / 7 / 2012$ & $17 / 7 / 2013$ & 363 & 400 & 2.2 & 3.1 \\
\hline B28 & 993 & C & $18 / 7 / 2013$ & $6 / 12 / 2013$ & 142 & 368 & 1.4 & 1.6 \\
\hline B30 & 1022 & $A$ & $4 / 1 / 2013$ & $10 / 12 / 2013$ & 341 & 678 & 2.2 & 3.4 \\
\hline B30 & 1022 & B & $11 / 12 / 2013$ & $18 / 9 / 2014$ & 282 & 633 & 2.0 & 2.0 \\
\hline B30 & 1022 & C & $19 / 9 / 2014$ & $19 / 1 / 2016$ & 488 & 743 & 2.1 & 2.0 \\
\hline B30 & 1051 & $A$ & $19 / 12 / 2014$ & $13 / 10 / 2015$ & 298 & 378 & 2.1 & 9.6 \\
\hline B30 & 1051 & B & $14 / 10 / 2015$ & $30 / 6 / 2016$ & 261 & 339 & 1.2 & 1.1 \\
\hline B33 & 964 & $A$ & $11 / 5 / 2010$ & $9 / 5 / 2011$ & 364 & 1,595 & 1.8 & 3.8 \\
\hline B33 & 964 & B & $10 / 5 / 2011$ & $22 / 6 / 2012$ & 411 & 1,293 & 1.9 & 5.2 \\
\hline B33 & 964 & $\mathrm{C}$ & $23 / 6 / 2012$ & $22 / 2 / 2013$ & 244 & 766 & 1.8 & 2.8 \\
\hline B37 & 964 & $A$ & $22 / 10 / 2010$ & $27 / 8 / 2011$ & 310 & 1,036 & 1.9 & 3.1 \\
\hline B37 & 964 & B & $28 / 8 / 2011$ & $3 / 11 / 2012$ & 434 & 1,347 & 1.8 & 5.1 \\
\hline B37 & 964 & C & $4 / 11 / 2012$ & $16 / 8 / 2013$ & 286 & 1,082 & 1.6 & 3.6 \\
\hline B33 & 993 & $A$ & $17 / 1 / 2012$ & $9 / 1 / 2013$ & 359 & 1,205 & 1.8 & 4.2 \\
\hline B33 & 993 & B & $10 / 1 / 2013$ & $5 / 6 / 2014$ & 513 & 2,503 & 2.0 & 6.9 \\
\hline B33 & 993 & C & $6 / 6 / 2014$ & $24 / 12 / 2014$ & 201 & 834 & 1.6 & 2.3 \\
\hline B37 & 993 & $A$ & $8 / 4 / 2012$ & $15 / 5 / 2013$ & 403 & 1,391 & 1.8 & 4.7 \\
\hline B37 & 993 & B & $16 / 5 / 2013$ & $23 / 3 / 2014$ & 312 & 1,550 & 2.0 & 4.1 \\
\hline B37 & 993 & C & $24 / 3 / 2013$ & $2 / 1 / 2015$ & 285 & 1,365 & 1.9 & 3.6 \\
\hline B34 & 1022 & $A$ & $31 / 5 / 2013$ & $7 / 10 / 2014$ & 494 & 2,452 & 2.0 & 6.6 \\
\hline B34 & 1022 & B & $8 / 10 / 2014$ & $30 / 6 / 2016$ & 632 & 2,505 & 2.2 & 4.3 \\
\hline
\end{tabular}



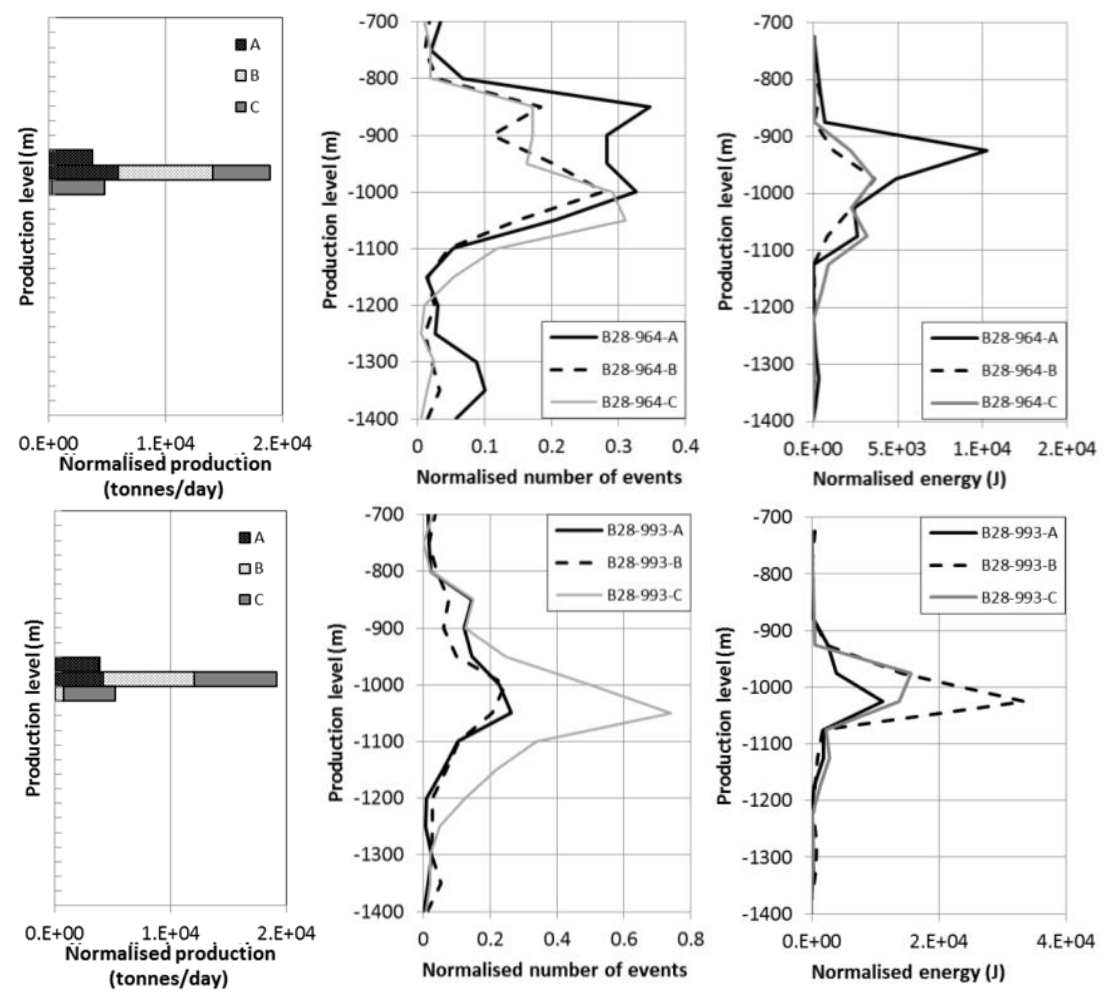

Figure 5 Production (left), number of events (middle) and cumulative energy (right) in $50 \mathrm{~m}$ bins for Block 28/30 for Level 964 (top) and 993 (bottom) (see Table 2). All parameters are normalised by the duration of the phase in days. The maximum observed magnitude in for different production levels and phases are shown in Table 2
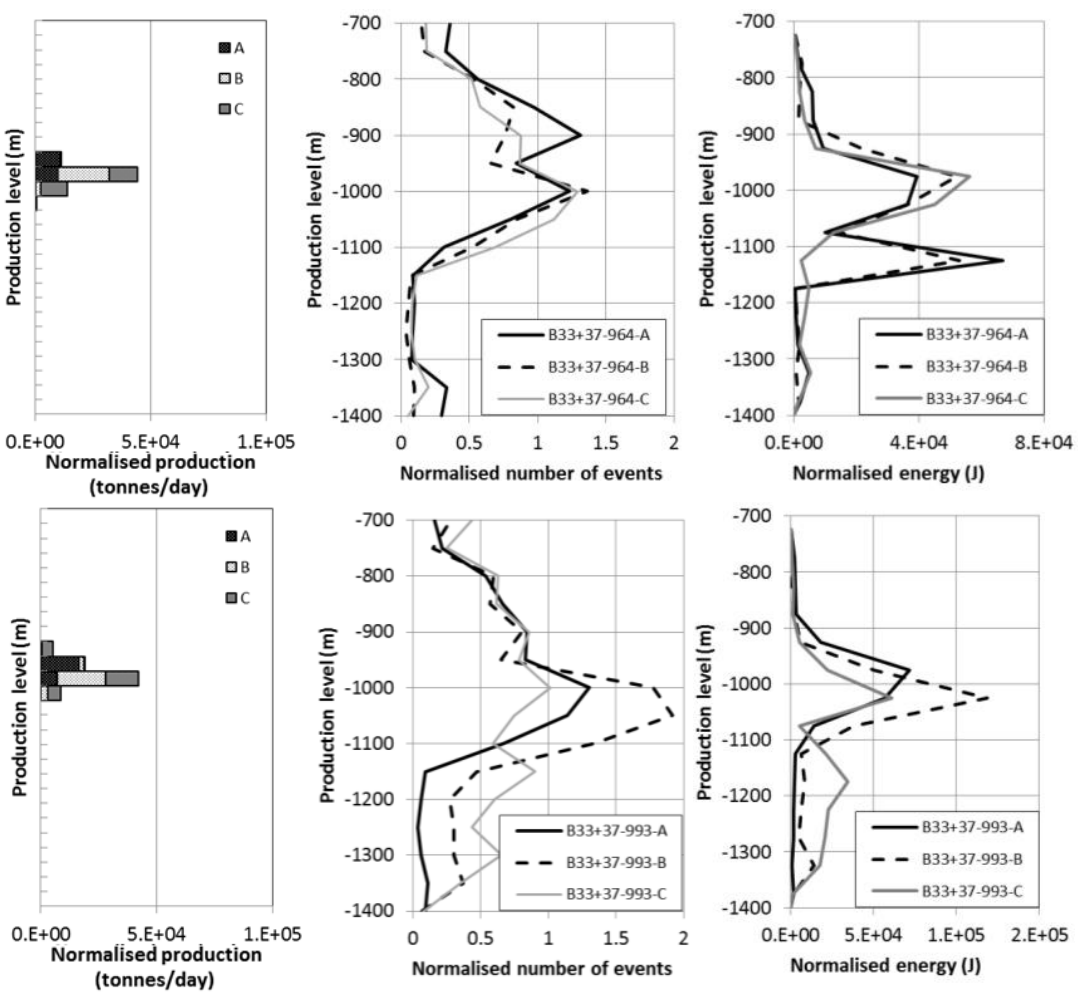

Figure 6 Production (left), number of events (middle) and cumulative energy (right) in $50 \mathrm{~m}$ bins for Block 33-37/34 for Level 964 (top) and 993 (bottom) (see Table 2). All parameters are normalised by the duration of the phase in days. The maximum observed magnitude in for different production levels and phases are shown in Table 2 


\subsection{Number of events as a function of production}

In order to check if there is direct correlation between the number of seismic events and the production volume (tonnes) we plotted both variables calculated for the same phases/blocks identified in Table 1 . The results are shown in Figure 7. As both the number of events and the production are for the same period of time they are not normalised by the duration of the phase. The results show a best correlation between the number of events and the production for Block $15 / 16\left(R^{2}=0.93\right)$, comparatively good correlation $\left(R^{2}=0.59\right)$ for Block 33-37/34, and poor correlation $\left(R^{2}=0.15\right)$ for Block $28 / 30$. It has to be noted that the correlation for Block $15 / 16$ is obtained only with five points, which might be the reason for the better correlation coefficient. The slope of the graphs is very different with the steepest one corresponding to Block $33-37 / 34$, which is also the most seismically active. The slope of the line for Block $28 / 30$ is between the slopes of the other two blocks. As the correlation coefficient for the latter block is very small, we can consider that there is no direct correlation between the number of seismic events and the production volume in tonnes for this block. Possibly there are some other factors that affect the seismicity more than the production (e.g. contrast in the geomechanical properties, geological structures). There are some indications that there is a seismically-active ore-parallel structure in Block 28/30 (Swedberg et al 2015; Malovichko et al 2015). More detailed investigation of seismicity in time and space is required to define the effect of different factors.

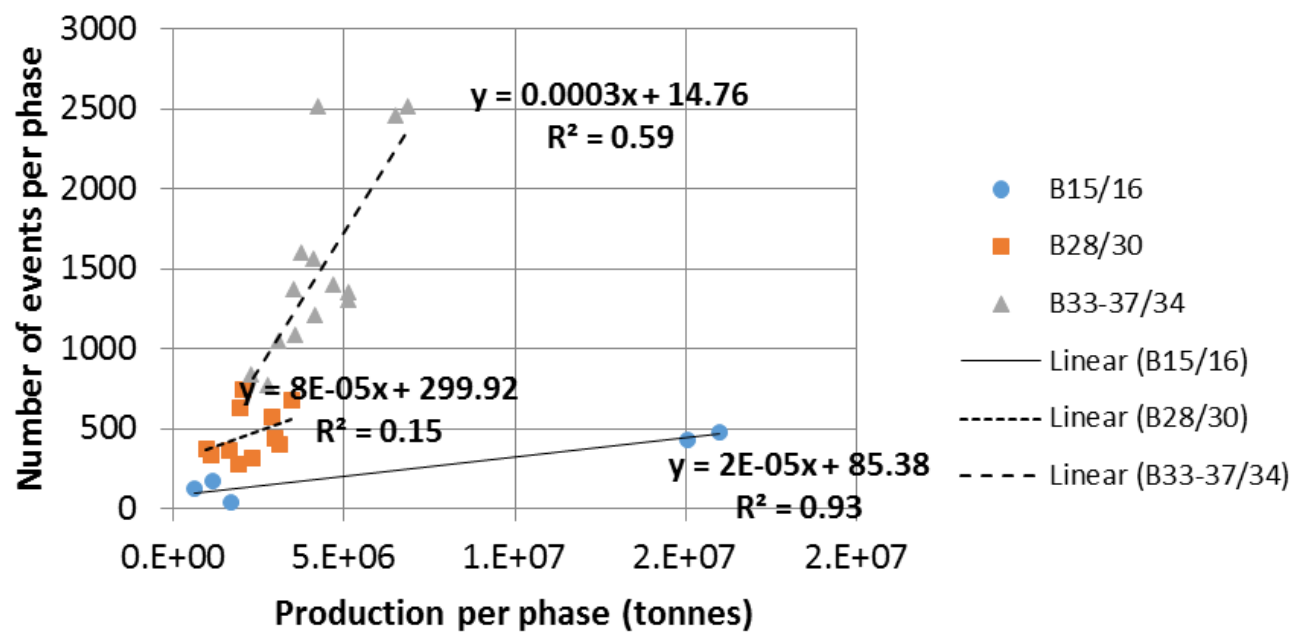

Figure 7 Number of events with $M>-0.4$ as a function of the production during each phase for Blocks $15 / 16,28 / 30$, and $33-37 / 34$

\section{$4 \quad$ Spatial variations in seismicity parameters depending on production stages}

Seismicity in mines is characterised not only by the number of seismic events, depth, magnitude, and energy but also by other parameters related to the source of the seismic events (seismic moment, stress drop, energy ratio $E_{s} / E_{p}$, energy index, etc.). One way to 'see' the spatial distribution of these parameters is to plot their cumulative numbers for a predefined grid. For this study a grid with dimensions $20 \times 20 \times 20 \mathrm{~m}$ was chosen. These dimensions are related to the accuracy of the hypocentre locations ( $20 \mathrm{~m})$. The cumulative number of events (density), cumulative seismic energy and the cumulative co-seismic deformation (defined as the sum of all seismic moments of the seismic events within the grid cell (Kostrov 1974) were plotted together with the production level. Examples of the spatial variations of the cumulative parameters are shown for Block 28 for Level 993 (Figure 8). 


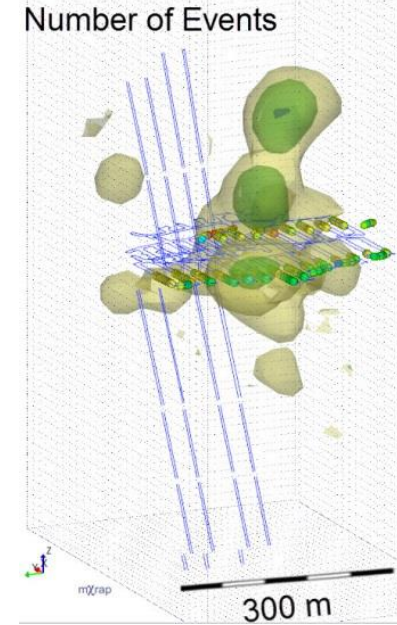

Normalised Cumulative Energy [J/t]

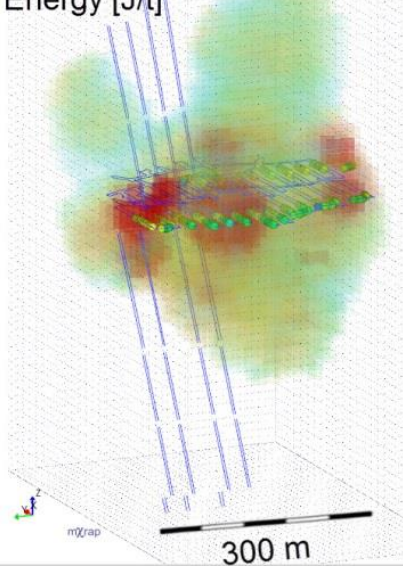

Normalised Cumulative Moment [Nm/t]

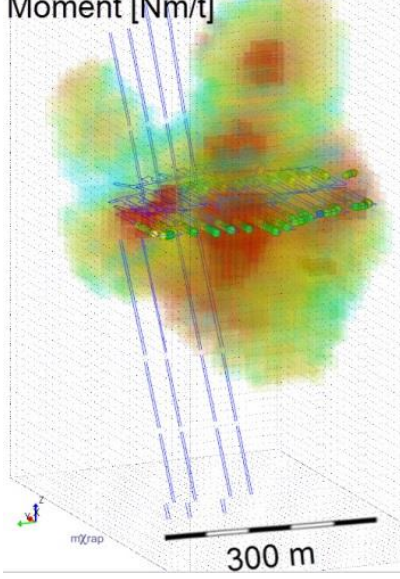

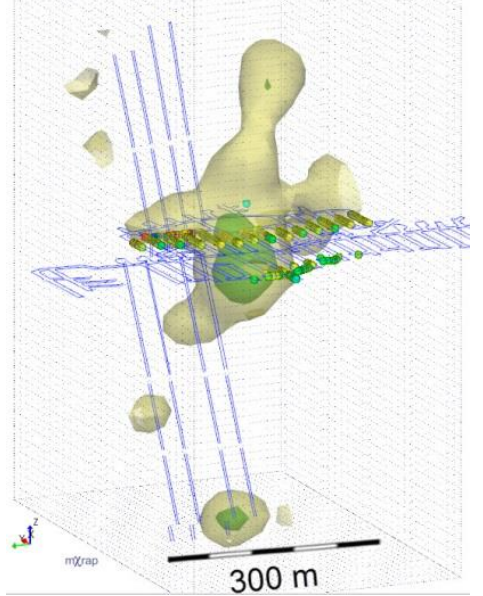
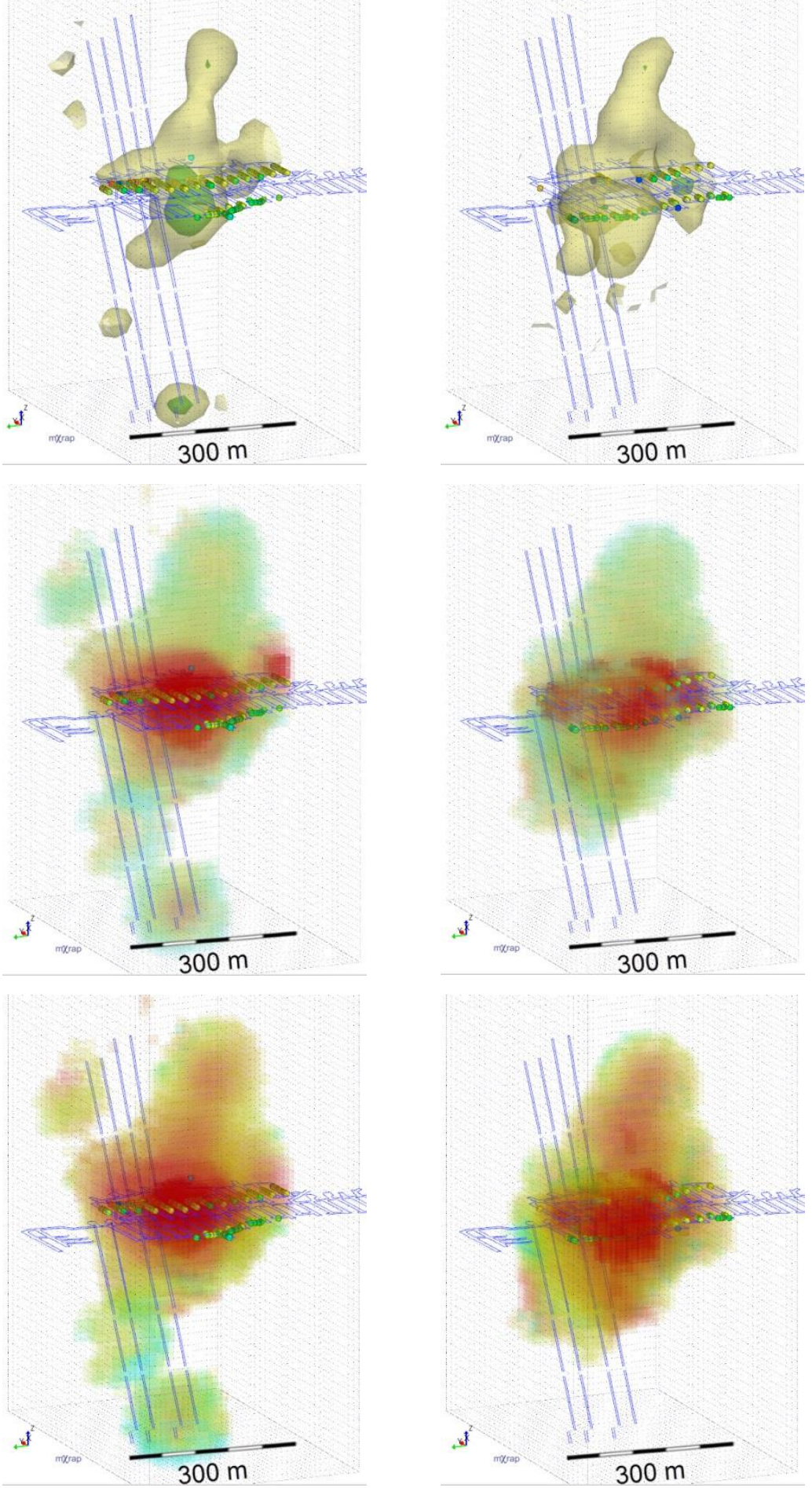

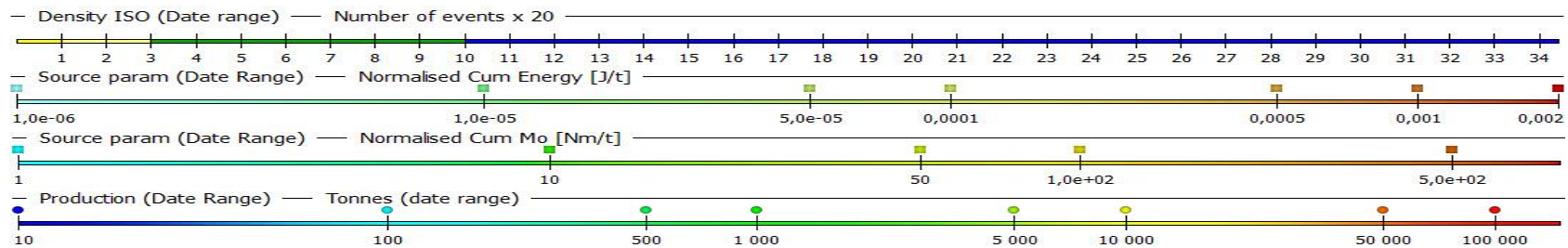

Figure 8 Example of spatial variations of number of seismic events, cumulative energy and cumulative seismic moment for Block 28, Level 993, opening (left), full production (middle), closing phases (right) $(M>-0.4)$. Position of production shown as spheres 
The examples show the cumulative spatial distributions of the three parameters (number of events, energy and seismic moment) around the production level. In Figure 8, Block 28, Level 993 there are maximum cumulative values for the three parameters around the production level, e.g. the largest energy is released in the areas with largest co-seismic deformation and number of events but there are also a lot of events and deformation above the production levels. For example there are certain areas where both energy release and deformation have a maximum but in some cases there is a lot of deformation without large seismic energy release. For some other levels and blocks there is also a large amount of energy release around and below the production with a maximum deformation above, around and below the production (e.g. Block 30, Level 1022). There is no clear trend in the spatial variation of the seismic source parameters from Phases $A$ to $C$.

In Figure 8, Phase B, there is cumulative energy release and deformation much lower than the production levels, along the orepasses. Similar observations were made also for other blocks and levels. Our interpretation is that the events around the orepasses are not completely removed. Different approaches of removal of orepass events were applied but this happened to be a very complicated problem as many of the events around the orepasses are actual shear events, not just 'noise' of falling rocks. The problem of the seismic hazard from seismic events around the orepasses has to be investigated further and more sophisticated methods to be developed for their separation from other types of events.

Some interesting observations can be made from the plots showing the average static stress drop and energy index for the three phases in Figure 9, Block 28, Level 993. The static stress drop is defined as the average difference between the initial and final (shear) stresses after a seismic event (Brune 1970), while the energy index (El, defined as the ratio between the seismic energy released from a seismic event and the expected radiated seismic energy) is an expression of stress variations in the rock mass - El > 1 indicates more energy is released for the seismic event than expected and shows stress increases in the rock mass, and EI $<1$ indicates less energy released for the seismic event than expected and shows that the rock mass may be distressing/relaxing or yielding (van Aswegen \& Butler 1993).

For the case on Figure 9 (top graphs) the average stress drops showed increased values on the footwall side - around the production level in Phase A, below the production in Phase $B$, and only on the edges around and below the production level in Phase C. In other cases, e.g. Block 33-37, the same Level 993, there is consistent trend of higher average stress drops on the footwall side at the production level for Phase $A$, and a maximum moving below the production level in Phases B and C.

The energy index plots show clearly $\mathrm{El}<1$ ( $\log \mathrm{El}<0$ ) (yielding rock mass) around and above the production levels on the footwall side (Figure 9, bottom graphs). Similar observation was made also for many other cases of the levels in studied blocks. El $>1$ ( $\log E \mathrm{El}>0$ ) (stress increase) is observed on the edges of the block around the production level and below in Phase B, and on the edges around the production level and below in Phase $C$. In other cases the area with $\mathrm{El}>1$ is spreading and moving under the production levels on the footwall side in Phases B and C. The indications of increased stresses on the footwall side below the production levels are in line with the results from the numerical modelling (Vatcher et al. 2014).

It is interesting to note that the spatial configurations of average static stress drop and El are very similar, with areas with larger static stress drop corresponding to areas with EI >1 and vice versa. The results show that some areas around and above the production level experience destressing while the areas below the production level on the footwall side are in a state of increased stress. This is only a first look at these parameters. More work needs to be done on the interpretation of the results by comparison with the results from numerical modelling. 

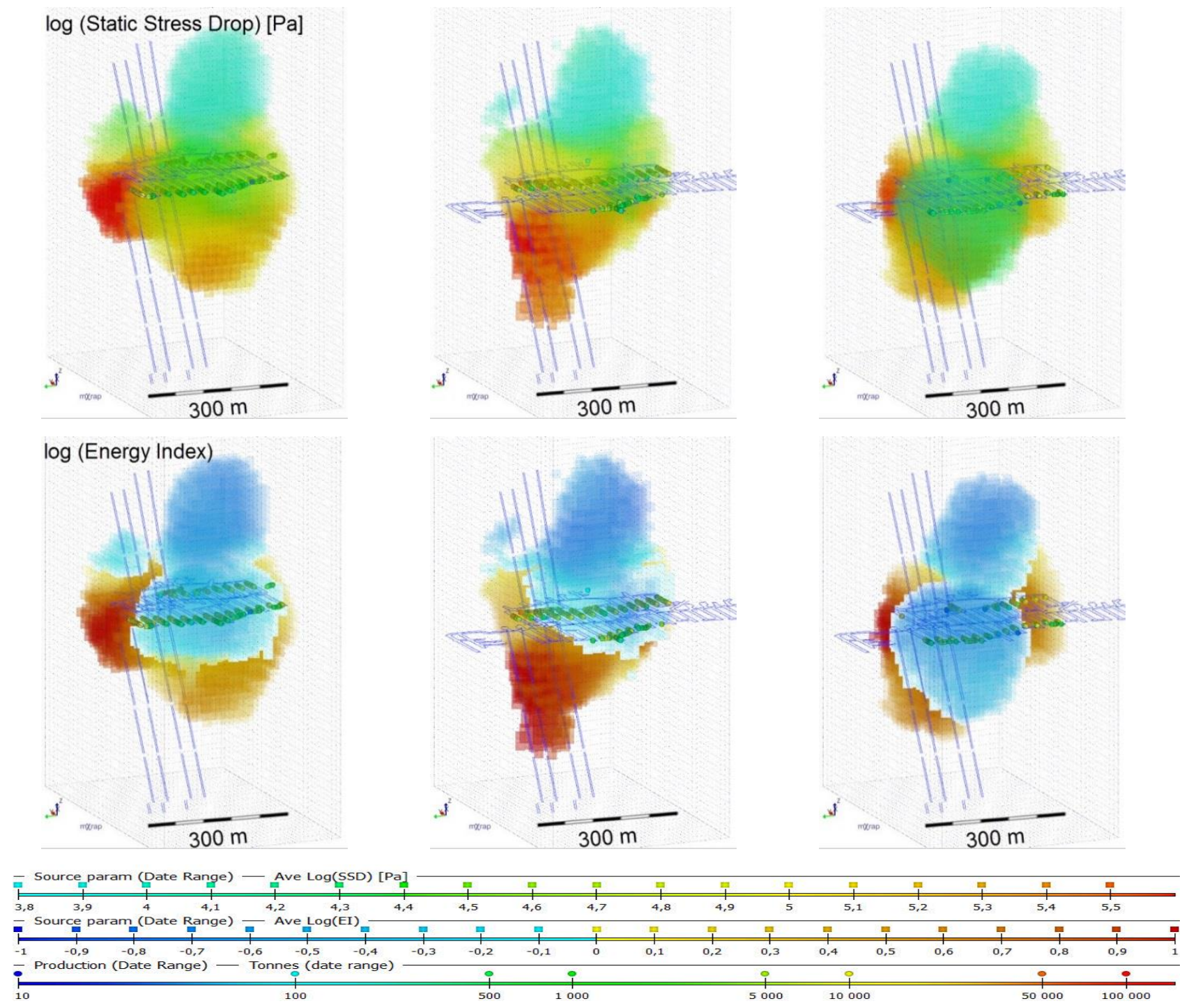

Figure 9 Example of spatial distribution of the average static stress drop (SSD, top) and logarithm of energy index (EI, bottom) for Block 28, Level 993, opening (left), full production (middle) and closing phases (right) $(M>-0.4)$. The position of the production is shown as spheres

\section{Conclusion}

The results of this study allowed us to look at the development of the seismic process during production from 2008 until 2016. The main conclusions that we can make at this moment using mostly visual comparison between the production and the seismicity (number of events, seismic energy, and co-seismic deformation, static stress drop, and energy index) are:

- The three studied blocks $15 / 16,28 / 30$ and $33-37 / 34$ show seismicity with very different behaviour. The number of events per year for Block $15 / 16$ is lowest, with a maximum observed magnitude decreasing with time slightly ( 0.2 magnitude units). The number of events per year in Block 28/30 is higher than in Block 15/16, with almost no change for events with $M>0$ but peak for the larger events $(M>1)$ in Period 3. The maximum observed magnitude for this block increased almost by 0.9 magnitude units from 1.3 to 2.2 from Period 1 to Period 3, followed by a small decrease. The number of events per year for Block 33-37/34 is much larger than in the other two blocks. This conclusion is valid also when we take into account the difference in the volume of the blocks and the seismically active volumes within them. The maximum observed magnitude stayed around 1.8 to 2.0 during the whole studied period of time. 
- In general a straightforward correlation between the production volume and number of larger events $(M>0)$ was not found for the three studied blocks. There is some correlation between the production in tonnes for all different phases that were identified and the number of seismic events during the same phases for Block $15 / 16\left(R^{2}=0.93\right)$. The correlation for block 33-37/34 is with much smaller correlation coefficient $\left(R^{2}=0.59\right)$. A very week correlation is observed for Block $28 / 30$, which may show that there are some other factors that affect the seismicity more than the production (e.g. areas with contrast in the geomechanical properties, geological structures, etc.). More detailed investigation of seismicity in time and space (for smaller time intervals) is required to define the effect of different additional factors on seismicity.

- Spatial distributions of cumulative seismic parameters calculated on a grid $20 \times 20 \times 20 \mathrm{~m}$ show the largest energy concentration around and below the production levels on the footwall side.

- The areas of largest cumulative seismic moment (deformation) correlate with the areas with the maximum number of events, concentrated around and above the production levels (indicating caving around these areas). Starting from Level 1,022 the maximum in deformation moves downwards, indicating also orepass caving.

- Static stress drop is highest around the production levels on the footwall side and below, mostly around some of the orepasses. The El spatial distribution shows El $>1$ (increased stresses) around and below the production level and $\mathrm{EI}<1$ (yielding) around and above the production level.

- The areas with increased static stress drop and EI > 1 coincide with the locations of the largest seismic events (in the footwall and around the caving orepasses).

This study presents only the first overview of the seismicity, depth and spatial distribution of some seismic source parameters in Kiruna Mine. Much more detailed analyses must be done to establish a correlation between the seismicity and the factors that possibly cause it (production, depth, geological structures, contrast in geomechanical properties, etc.). It is obvious that smaller time intervals within the production phases should be considered in the future analysis. Further, more detailed study is required for correlation between the rock mechanical properties and the mine induced stress changes, and the stress indicators (stress drop and energy index).

\section{Acknowledgement}

We would like to express our appreciation to Johan Wesseloo and Paul Harris (Australian Centre for Geomechanics) for their help, contribution, and understanding in customisation of the mXrap software for this study. This work could not have been done without them. The financial support for this research is provided by LKAB, Hjalmar Lundbohm Research Center (HLRC)/LKAB, and Vinnova (The Swedish Governmental Agency for Innovation Systems).

\section{References}

Brune, JN 1970, 'Tectonic stress and the spectra of seismic shear waves from earthquakes', Journal of Geophysical Research, vol. 75, pp. 4997-5009.

Gutenberg, B \& Richter, CF 1956, 'Magnitude and energy of earthquakes', Annali di Geofisica, vol. 9, pp 1-15.

Harris, PC \& Wesseloo, J 2015, mXrap software, version 5, Australian Centre for Geomechanics, The University of Western Australia, Perth, http://www.mXrap.com

Kijko, A 2004, 'Estimation of the maximum earthquake magnitude, mmax', Pure and Applied Geophysics, vol. 161, no. 8, pp. 1655-1681.

Kijko, A \& Funk, CW 1994, 'The assessment of seismic hazards in mines', Journal of the South African Institute of Mining and Metallurgy, vol. 94, no. 7, pp. 179-185.

Kijko, A \& Graham, G 1998, 'Parametric-historic procedure for probabilistic seismic hazard analysis. Part I: Estimation of maximum regional magnitude mmax', Pure and Applied Geophysics, vol. 152, no. 3, pp. 413-442.

Kijko, A \& Sellevoll, MA 1989, 'Estimation of earthquake hazard parameters from incomplete data files. Part I: Utilization of extreme and complete catalogs with different threshold magnitudes', Bulletin of the Seismological Society of America, vol. 79, no. 3, pp. 645-654. 
Kostrov, B 1974, 'Seismic moment and energy of earthquakes and seismic flow of rock', Physics of Solid Earth, no. 1, pp. 23-40.

Lasocki, S \& Urban, P 2011, 'Bias, variance and computational properties of Kijko's estimators of the upper limit of magnitude distribution, Mmax', Acta Geophysica, vol. 59, no. 4, pp. 659-673.

Malovichko, DA, Lötter, EC \& Meyer, SG 2015, Kiruna Mine: Analysis of two large seismic events of interest (m2.2 on 12 July 2013 and m2.1 on 29 May 2014), IMS final report, KIRUNA-REP-LRGEVENTS-201407.

Swedberg, E, Anderson, UB, Boskovic, M, Dahner-Lindkvist, C, Woldemedhin, B, Töyra, J \& Myrzell, M 2015, Roackfall on levels $1079 \mathrm{~m}$ and $1108 \mathrm{~m}$, block 30, 2014-05-29, at Kiirunavaara Mine, Internal LKAB report 15-887 (in Swedish).

van Aswegen, G \& Butler, AG 1993, 'Applications of quantitative seismology in South African gold mines', in P Young (ed.), Proceedings of the 3rd International Symposium on Rockburst and Seismicity in Mines, AA Balkema, Rotterdam, pp. 261-266.

Vatcher, J, McKinnon, SD \& Sjöberg, J 2014, 'Mine-scale numerical modelling, seismicity and stresses at Kiirunavaara mine, Sweden', in MR Hudyma \& Y Potvin (eds), Proceedings of the Seventh International Seminar on Deep and High Stress Mining, Sudbury, Canada, Australian Centre for Geomechanics, Perth, pp. 363-376.

Wesseloo, J \& Harris, PC 2015, mXrap Software App, Mining Induced Seismicity - Grid Based Analysis, version 1, Australian Centre for Geomechanics, The University of Western Australia, Perth, http://www.mXrap.com

Wesseloo, J, Woodward, K \& Pereira, J 2014, 'Grid-based analysis of seismic data', Journal of the Southern African Institute of Mining and Metallurgy, vol. 114, no. 10, pp. 815-822. 
